\title{
Effect of interstitial hydrogen on structural and electronic properties of $\mathrm{BaTiO}_{3}$
}

\author{
Arvids Stashans $†$ and Johnny Chimborazo \\ Centro de Investigación en Física de la Materia Condensada, Corporación de \\ Física, Fundamental y Aplicada, Apartado 17-12-637, Quito, Ecuador
}

[Received 12 December 2001 and accepted 31 December 2001]

\begin{abstract}
We investigate the geometry and electronic structure of an interstitial $\mathrm{H}$ atom in the $\mathrm{BaTiO}_{3}$ crystal considering both cubic and tetragonal crystallographic lattices. A quantum-chemical method based on the Hartree-Fock formalism is used throughout the study. Interstitial $\mathrm{H}$ is found to bind to one of the $\mathrm{O}$ atoms, forming the so-called $\mathrm{OH}$ group. At equilibrium, the $\mathrm{O}-\mathrm{H}$ distances are found to be 0.89 and $0.91 \AA$ for cubic and tetragonal lattices respectively. The performed automated geometry optimization procedure of the defective region shows considerable outward movements of atoms closest to the impurity. The role of the $\mathrm{H}$ impurity in ferroelectric polarization in the $\mathrm{BaTiO}_{3}$ crystal is analysed using the results obtained in connection with the available experimental data on ferroelectric perovskites.
\end{abstract}

\section{$\S 1$. INTRODUCTION}

The perovskites are an extremely important class of ceramic materials which are now the focus of extensive study. Because of its large electro-optic coefficients and high photorefractive sensitivity (Feinberg et al. 1980), $\mathrm{BaTiO}_{3}$ is of special interest. Knowledge of the specific features of possible defects in a photorefractive compound is necessary in order to optimize the performance of the material, such as speed and maximum refractive index changes. This material also exhibits ferroelectric and piezoelectric properties and therefore finds increasing processibility as an active element in microelectronic devices. Additionally, $\mathrm{BaTiO}_{3}$ is a promising material for self-pumped phase conjugation or holographic storage (Krätzig et al. 1980, Feinberg 1982) and inexpensive diode lasers (Rytz et al. 1990).

It is known that the main properties of perovskite crystals are strongly influenced by the presence of point defects. $\mathrm{H}$ is a ubiquitous impurity and its role in structural and electronic properties of $\mathrm{BaTiO}_{3}$ is not yet elucidated sufficiently. An important issue concerning the $\mathrm{H}$ impurity in $\mathrm{BaTiO}_{3}$ is its effect on the ferroelectric polarization. When ferroelectrics are used in conjunction with $\mathrm{Si}, \mathrm{H}$ contamination during $\mathrm{Si}$ passivation can result in a loss of ferroelectricity. However, results from a number of experiments indicate that a main source of degradation (Zafar et al. 1997, Ikarashi 1998, Kushida-Abdelghafa $\mathrm{r}$ et al. 1999) is H-induced chemical changes at metaloxide interfaces. It has also been suggested that $\mathrm{H}$ can induce the loss of bulk

†Email: sauleskalns@yahoo.com.

Philosophical Magazine B ISSN 1364-2812 print/ISSN 1463-6417 online (C) 2002 Taylor \& Francis Ltd 
ferroelectricity in perovskite ferroelectrics where $\mathrm{O}$ loss at the interface is not significant (Aggarwal et al. 1998). Despite numerous studies on the $\mathrm{H}$ impurity in ferroelectric $\mathrm{BaTiO}_{3}$ and $\mathrm{PbTiO}_{3}$ crystals, no clear understanding of the theoretical basis of $\mathrm{H}$-atom behaviour in these materials exists. Thus the main purpose of our research is to find equilibrium positions of the $\mathrm{H}$ atom in cubic and tetragonal lattices of the $\mathrm{BaTiO}_{3}$ crystal and to discover possible impurity-atom effects upon the electronic structure of the crystal and, furthermore, its influence on ferroelectricity in the tetragonal phase of the $\mathrm{BaTiO}_{3}$ crystal.

In our studies we have chosen to use the intermediate neglect of differential overlap approach developed especially for periodic systems, for example crystal studies. Our method as implemented in the CLUSTERD computer code (Stefanovich et al. 1990) is based on a strict and reliable parametrization scheme (Shluger 1985). This technique has its origin in molecular orbital (MO) theory and has been found to be very reliable in the treatment of the electronic and spatial structure of perfect and defective crystals. Some examples include investigation of hole polarons (Jacobs and Kotomin 1992, Jacobs et al. 1993) and F-type complexes (Stashans et al. 1994, Kotomin et al. 1995) in the corundum $\left(\alpha-\mathrm{Al}_{2} \mathrm{O}_{3}\right)$ crystal, impurity intercalation studies in the $\mathrm{TiO}_{2}$ crystal (Stashans et al. 1996a, b, Lunell et al. 1997), H-atom studies in zincblende structure semiconductors (Stashans and Kitamura 1996, 1997) and the equilibrium position detection for $\mathrm{H}$ impurities in the $\mathrm{WO}_{3}$ crystal (Stashans and Lunell 1996).

\section{§2. BRIEF OUTLINE OF THE METHOD}

The method is based on the MO theory and a periodic large-unit-cell (LUC) model. This approach considers the electronic band structure and calculates the total energy of the system very accurately owing to not only the periodicity condition but also a careful treatment of the exchange interaction. This is very important since titanate crystals have considerable covalency effects in the chemical bonding, which have to be taken into account to obtain a reliable outcome. A full account of the method used to calculate the total energy of the crystal within the LUC framework has been given by Stefanovich et al. (1990). The main idea of the LUC approximation is that the Fock matrix elements are made self-consistent through terms of the form

$$
\frac{1}{N} \sum_{k} P_{p q}(\mathbf{k}) \exp \left(\mathrm{ik} \cdot \mathbf{R}_{v}\right)
$$

where the summation is carried out over the values $\mathbf{k}$ in the reduced Brillouin zone (BZ) of the LUC. It has been proved (Shluger and Stefanovich 1990) that the computation of the electronic structure of the unit cell at $\mathbf{k}=\mathbf{0}$ in the reduced $\mathrm{BZ}$ is equivalent to a band-structure calculation at those $\mathrm{BZ} \mathbf{k}$ points which transform to the reduced $\mathrm{BZ}$ centre on extending the primitive unit cell. As indicated by numerous studies (Kantorovich et al. 1994, Stashans and Kitamura 1997, Zhukovskii et al. 1997, Persson et al. 1998), a fourfold- or eightfold-symmetric extension of the primitive unit cell proves to be completely sufficient to reproduce correctly the electronic band structure of the crystal. We have used an eightfold $(2 \times 2 \times 2)$ extended LUC to study the $\mathrm{H}$ impurity in the $\mathrm{BaTiO}_{3}$ crystal.

The numerical parameters for the $\mathrm{BaTiO}_{3}$ crystal have been obtained before reproducing the most important properties of this material and also in studies of 
Table 1. Semiempirical parameter sets used in the present work: $\zeta, E_{\text {neg }}, P^{0}$ and $\beta$.

\begin{tabular}{lccrcc}
\hline Atom & $\mathrm{AO}$ & $\begin{array}{c}\zeta \\
(\mathrm{au})\end{array}$ & $\begin{array}{r}E_{\text {neg }} \\
(\mathrm{eV})\end{array}$ & $\begin{array}{c}P^{0} \\
\text { (electrons) }\end{array}$ & $\begin{array}{c}\beta \\
(\mathrm{eV})\end{array}$ \\
\hline $\mathrm{Ba}$ & $6 \mathrm{~s}$ & 1.65 & 6.2 & 0.2 & -0.4 \\
& $5 \mathrm{p}$ & 2.8 & 34.6 & 2.0 & -4.0 \\
$\mathrm{Ti}$ & $4 \mathrm{~s}$ & 1.4 & 3.7 & 0.65 & -0.5 \\
& $4 \mathrm{p}$ & 1.1 & -15.0 & 0.04 & -0.5 \\
& $3 \mathrm{~d}$ & 1.93 & 7.2 & 0.55 & -9.0 \\
$\mathrm{O}$ & $2 \mathrm{~s}$ & 2.27 & 4.5 & 1.974 & -16.0 \\
& $2 \mathrm{p}$ & 1.86 & -12.6 & 1.96 & -16.0 \\
$\mathrm{H}$ & $1 \mathrm{~s}$ & 1.2 & 4.0 & 0.8 & -2.0 \\
\hline
\end{tabular}

Table 2. Two-centre parameters $\alpha_{\mu \mathrm{B}}$ where $\mu \in \mathrm{A}$.

\begin{tabular}{lcccc}
\hline & \multicolumn{4}{c}{$\alpha_{\mu \mathrm{B}}\left(\mathrm{au}^{-1}\right)$} \\
\cline { 2 - 5 } $\mathrm{A}$ & $\mathrm{B}=\mathrm{Ba}$ & $\mathrm{B}=\mathrm{Ti}$ & $\mathrm{B}=\mathrm{O}$ & $\mathrm{B}=\mathrm{H}$ \\
\hline $\mathrm{Ba}$ & 0.20 & 0.10 & 0.57 & 0.00 \\
$\mathrm{Ti}$ & 0.53 & 0.13 & 0.38 & 0.00 \\
$\mathrm{O}$ & 0.36 & 0.10 & 0.15 & 0.23 \\
$\mathrm{H}$ & 0.00 & 0.00 & 0.42 & 0.33 \\
\hline
\end{tabular}

other crystals. In particular, parameters for the $\mathrm{O} 2 \mathrm{~s}$ and $2 \mathrm{p}$ atomic orbitals (AOs) and the H 1s AO are taken from the work of Stefanovich et al. (1990), for the Ti 4s, $4 \mathrm{p}$ and $3 \mathrm{~d}$ AOs as well as for the Ba 6s and 5p AOs from the work of Pinto and Stashan s (2000). As one can see, we have restricted ourselves to the use of the valence basis set. The parameters utilised are given in tables 1 and 2 .

It is important to note that the current computational method has already been applied to titanates, giving encouraging results. In particular, we have studied $\mathrm{Nb}$ doping in the cubic and orthorhombic phases of the $\mathrm{CaTiO}_{3}$ crystal (Erazo and Stashans 2000), hole polarons and impurity centres in the $\mathrm{BaTiO}_{3}$ crystal (Pinto and Stashans 2000, Pinto et al. 2000, Stashans and Pinto 2000, Patiño et al. 2001) as well as point-defect studies in the $\mathrm{SrTiO}_{3}$ crystal bulk and surface (Sánchez and Stashans 2001, Stashans 2001, Stashans et al. 2001).

\section{§3. RESULTS AND DISCUSSION}

As was mentioned above, an eightfold- or even fourfold-symmetric extension of the primitive unit cell proves to be sufficient to reproduce correctly the geometry and electronic density distribution of a given crystal. Hence we have chosen to exploit the 40-atom LUC, which corresponds to the eightfold $(2 \times 2 \times 2)$ extension of the primitive five-atom unit cell. Additionally, one $\mathrm{H}$ atom was inserted in the middle of the LUC, thus giving us the system consisting of 41 atoms. The LUC size was considered to be sufficient to avoid any mutual defect-defect interaction since the H-atom influence does not extend much in the lattice (Stashans and Kitamura 1996, 1997). 
Therefore, our model could be called the study of a single point defect within the periodic model.

\subsection{Characteristics of the $O-H$ bonding}

In order to find the minimum-energy configuration we have investigated a number of possible sites for the $\mathrm{H}$ intercalation. Different types of $\mathrm{H}$ geometry optimization have been performed including automated geometry optimization using the downhill simplex method in multidimensions (Press et al. 1986). As a result the obtained $\mathrm{H}$ equilibrium position is shown in figure 1.

The impurity atom is located almost within the horizontal $x-y$ plane formed by the $\mathrm{O}$ atoms. The calculated distances of the $\mathrm{O}-\mathrm{H}$ bond length are found to be equal to 0.89 and $0.91 \AA$ in the cubic and tetragonal phases respectively. The $\mathrm{O}-\mathrm{H}$ bond axis is found to be almost parallel to the $x$ axis. The computed bond lengths are shorter than the value of $0.97 \AA$ in a free $\mathrm{OH}^{-}$group (Huber and Herzberg 1979). Here one has to consider the $\mathrm{OH}^{-}$group instead of a neutral $\mathrm{OH}$ molecule since the electronic density analysis gives us $-0.82 e$ and $-0.75 e$ for this complex in the cubic and tetragonal structures, respectively. We explain the shorter bond length for the $\mathrm{OH}^{-}$complex as due to the rather compact crystalline packing in the $\mathrm{BaTiO}_{3}$ crystal. It is worth mentioning that recently performed first-principle pseudopotential

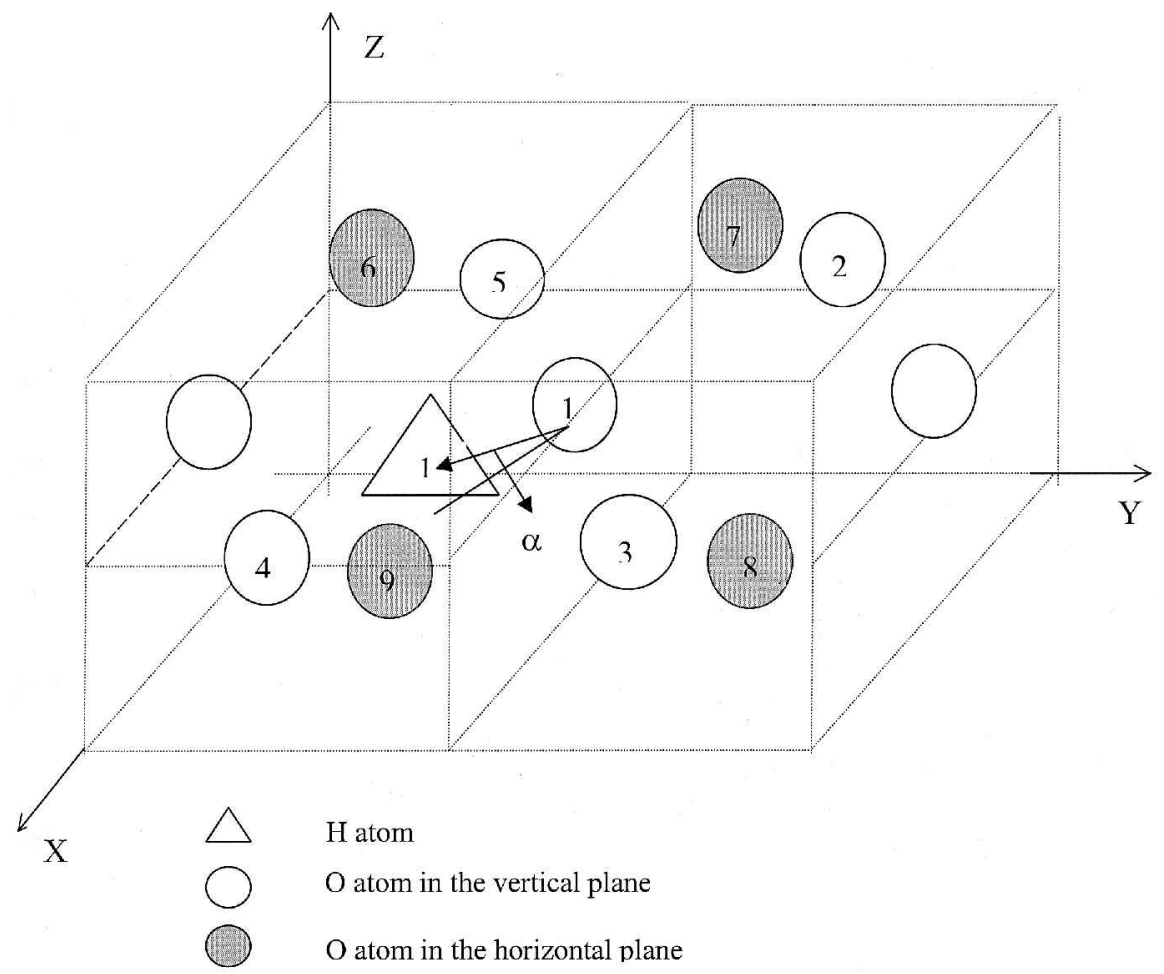

Figure 1. A schematic diagram describing the $\mathrm{H}$ equilibrium position in the $\mathrm{BaTiO}_{3}$ crystal. White and grey circles indicate $\mathrm{O}$ atoms located in the middle of vertical and horizontal planes respectively. The impurity atom is located just above the plane formed by $\mathrm{O}(2), \mathrm{O}(3), \mathrm{O}(4)$ and $\mathrm{O}(5)$ atoms and forms an angle $\alpha$ with this plane. $\alpha=4.00^{\circ}$ and $\alpha=8.76^{\circ}$ for the cubic and tetragonal lattices respectively. 
calculations based on the local-density approximation of the $\mathrm{H}$ atom in the $\mathrm{PbTiO}_{3}$ crystal (Park and Chadi 2000) also showed a considerable reduction in the $\mathrm{O}-\mathrm{H}$ bond length in the $\mathrm{PbTiO}_{3}$ crystal. Obviously the shortening of the $\mathrm{O}-\mathrm{H}$ bond is a common feature in the titanates because of their compact crystalline lattice.

\subsection{Lattice response to the $H$ incorporation}

The presence of an impurity perturbs the crystalline lattice and, as a result, the atoms closest to the defect move to their new equilibrium sites. The atomic displacements in the cubic structure of the $\mathrm{BaTiO}_{3}$ crystal show the following pattern. The two Ti atoms closest to the $\mathrm{O}-\mathrm{H}$ group move outwards by approximately $0.1 \AA$. The four $\mathrm{Ba}$ atoms exhibit the same pattern in their displacements. The two Ba atoms closest to the $\mathrm{H}$ impurity move away about $0.17 \AA$ while the two next-closest $\mathrm{Ba}$ atoms are displaced by $0.04 \AA$. The movements of positively charged atoms surrounding the defect are clearly understood if one considers the following two physical effects. Firstly, the $\mathrm{H}$ atom is charged positively and thus, owing to the Coulomb interaction, the $\mathrm{Ba}$ and $\mathrm{Ti}$ atoms move outwards. Secondly, insertion of the $\mathrm{H}$ impurity is accompanied by the creation of the chemical bond between this $\mathrm{H}$ atom and one of the $\mathrm{O}$ atoms, $\mathrm{O}(1)$. As a result the chemical bonds between the $\mathrm{O}(1)$ atom and the surrounding $\mathrm{Ti}$ and $\mathrm{Ba}$ atoms are weakened, leading to the outward displacements of these atoms. The $\mathrm{Ba}$ and $\mathrm{Ti}$ atoms form two atomic spheres surrounding the defect most closely. Since both spheres move outwards, it also provokes the outward movement of some atoms situated in the third sphere surrounding the defect, which consists of the $\mathrm{O}$ atoms. Thus we can explain the outward movements of $\mathrm{O}(4)$ and $\mathrm{O}(5)$ atoms, which receive an imaginary 'push' from the atoms of the first two spheres closest to the defect. Complete information on lattice relaxation in the cubic phase of the crystal is given in table 3 and figure 2. Finally, we would like to note that the atomic displacements are not radial with respect to the geometric centre of the system, that is the $\mathrm{O}-\mathrm{H}$ group. This is expected because the $\mathrm{H}$ insertion lowers considerably the local symmetry in the defective region of the $\mathrm{BaTiO}_{3}$ lattice.

As one can observe, the lattice relaxation in the tetragonal structure of the $\mathrm{BaTiO}_{3}$ crystal shows a similar pattern (table 4 and figure 3). Because of the lower initial symmetry of the crystal, that is the tetragonal crystallographic structure, the atomic movements are even less ordered. We would like to point out the rather large

Table 3. Outward displacements $d$ of atoms in the defective region of the cubic $\mathrm{BaTiO}_{3}$ crystal. Atomic numeration corresponds to that given in figure 2 .

\begin{tabular}{lc}
\hline Atom & $\begin{array}{c}d \\
(\AA)\end{array}$ \\
\hline $\mathrm{Ba}(1)$ & 0.16 \\
$\mathrm{Ba}(2)$ & 0.18 \\
$\mathrm{Ba}(3)$ & 0.04 \\
$\mathrm{Ba}(4)$ & 0.04 \\
$\mathrm{Ti}(1)$ & 0.10 \\
$\mathrm{Ti}(2)$ & 0.09 \\
$\mathrm{O}(4)$ & 0.12 \\
$\mathrm{O}(5)$ & 0.12 \\
\hline
\end{tabular}




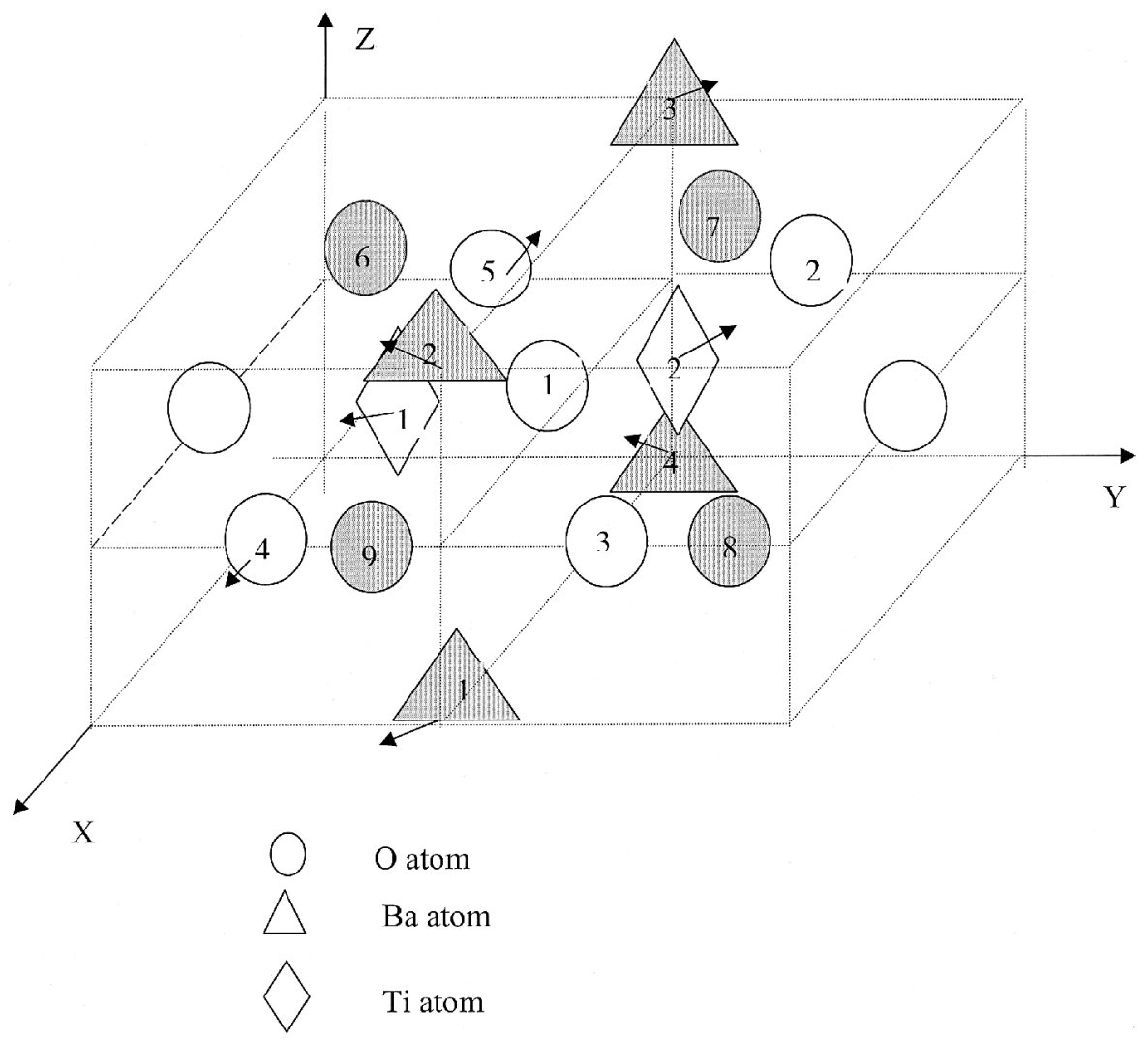

Figure 2. Lattice relaxation in the cubic phase. The arrows show outward displacements of the atoms (with respect to the defect) in the defective region. The $\mathrm{H}$ atom is not shown in the figure for simplicity but it forms a chemical bond with the $\mathrm{O}(1)$ atom and thus is situated along the positive $x$ direction.

Table 4. Outward displacements $d$ of atoms in the defective region of the tetragonal $\mathrm{BaTiO}_{3}$ crystal. Atomic numeration corresponds to that given in figure 3 .

\begin{tabular}{lc}
\hline Atom & $\begin{array}{c}d \\
(\AA)\end{array}$ \\
\hline $\mathrm{Ba}(1)$ & 0.08 \\
$\mathrm{Ba}(2)$ & 0.29 \\
$\mathrm{Ba}(3)$ & 0.09 \\
$\mathrm{Ba}(4)$ & 0.08 \\
$\mathrm{Ti}(1)$ & 0.12 \\
$\mathrm{Ti}(2)$ & 0.08 \\
$\mathrm{O}(4)$ & 0.12 \\
$\mathrm{O}(8)$ & 0.09 \\
$\mathrm{O}(9)$ & 0.09 \\
\hline
\end{tabular}




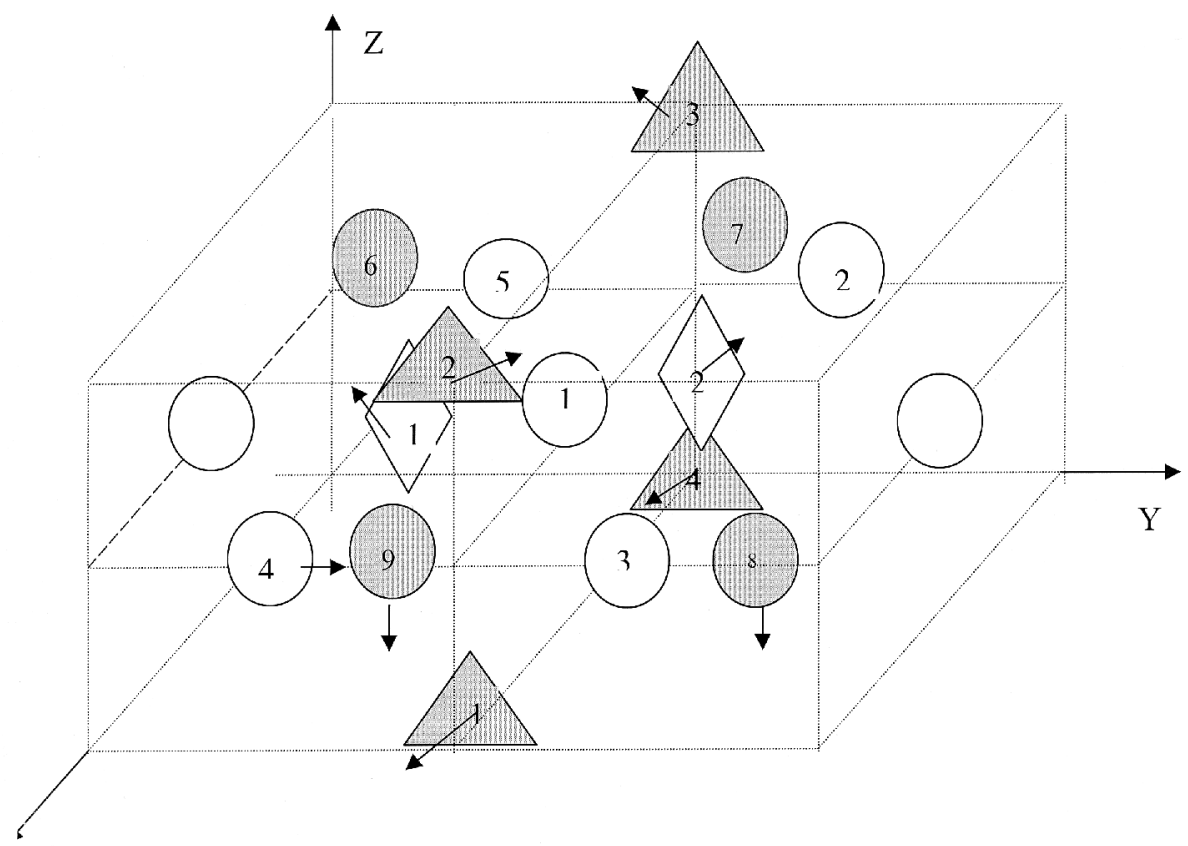

$\mathrm{X}$

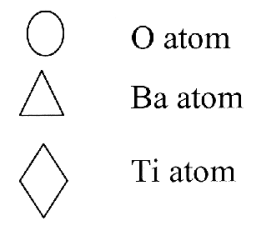

Figure 3. Lattice relaxation in the tetragonal phase. The arrows show outward displacements of the atoms (with respect to the defect) in the defective region. The $\mathrm{H}$ atom is not shown in the figure for simplicity but it forms a chemical bond with the $\mathrm{O}(1)$ atom and thus is situated along the positive $x$ direction. The component in atomic displacements along the vertical $z$ axis is considerably larger than the same variable in the cubic phase.

component of the displacements along the $z$ axis, especially for $\operatorname{Ti}(1)$ and $\mathrm{Ba}(2)$. This is normal since in the tetragonal phase the crystalline lattice is slightly extended along the $z$ axis; so the atoms have more freedom to displace along this direction.

\subsection{Analysis of the electronic properties in the $\mathrm{H}$-doped $\mathrm{BaTiO}_{3}$}

The $\mathrm{H}$ impurity in $\mathrm{BaTiO}_{3}$ is found to be an autoionized, positively charged ion since its donor level lies above the conduction-band bottom. In this positively charged state, the valence bands are fully occupied and there is no state in the bandgap. The interstitial $\mathrm{H}$ behaves, therefore, as a shallow donor.

The electron density analysis using the Löwdin method, carried out for the equilibrium structures as well as for the doped crystal without lattice relaxation, gives the following pattern. The $\mathrm{Ba}$ atoms closest to the impurity almost do not change their effective charges except for the $\mathrm{Ba}(1)$ and $\mathrm{Ba}(2)$ atoms in the cubic structure (tables 5 and 6). However, we observe considerable charge redistribution for the $\mathrm{Ti}$ and $\mathrm{O}$ atoms nearest to $\mathrm{H}$. From our results the $\mathrm{Ti}$ atoms tend to become less positive while the $\mathrm{O}$ atoms become less negative. This implies the redistribution 
Table 5. Charges on atoms in the defective region of the cubic $\mathrm{BaTiO}_{3}$ crystal: perfect crystal, $Q_{1}$; doped crystal without lattice relaxation, $Q_{2}$; equilibrium configuration of the doped crystal, $Q_{3}$. Atomic numeration corresponds to that given in figure 2 .

\begin{tabular}{lccc}
\hline & $Q_{1}$ & $Q_{2}$ & $Q_{3}$ \\
Atom & (units of $e$ ) & (units of $e$ ) & (units of $e$ ) \\
\hline $\mathrm{Ba}(1)$ & 1.88 & 1.87 & 1.81 \\
$\mathrm{Ba}(2)$ & 1.88 & 1.87 & 1.81 \\
$\mathrm{Ba}(3)$ & 1.88 & 1.88 & 1.88 \\
$\mathrm{Ba}(4)$ & 1.88 & 1.88 & 1.88 \\
$\mathrm{Ti}(1)$ & 2.25 & 1.90 & 2.16 \\
$\mathrm{Ti}(2)$ & 2.25 & 1.91 & 1.70 \\
$\mathrm{O}(1)$ & -1.38 & -1.35 & -1.25 \\
$\mathrm{O}(4)$ & -1.38 & -1.41 & -1.25 \\
$\mathrm{O}(5)$ & -1.38 & -1.36 & -1.37 \\
$\mathrm{H}(1)$ & - & 0.53 & 0.50 \\
\hline
\end{tabular}

Table 6. Charges on atoms in the defective region of the tetragonal $\mathrm{BaTiO}_{3}$ crystal: perfect crystal, $Q_{1}$; doped crystal without lattice relaxation, $Q_{2}$; equilibrium configuration of the doped crystal, $Q_{3}$. Atomic numeration corresponds to that given in figure 3 .

\begin{tabular}{lccc}
\hline $\begin{array}{c}Q_{1} \\
\text { Atom }\end{array}$ & $\begin{array}{c}Q_{2} \\
\text { (units of } e \text { ) }\end{array}$ & $\begin{array}{c}Q_{3} \\
\text { (units of } e \text { ) }\end{array}$ & (units of $e$ ) \\
\hline $\mathrm{Ba}(1)$ & 1.88 & 1.87 & 1.87 \\
$\mathrm{Ba}(2)$ & 1.88 & 1.87 & 1.86 \\
$\mathrm{Ba}(3)$ & 1.88 & 1.88 & 1.88 \\
$\mathrm{Ba}(4)$ & 1.88 & 1.88 & 1.88 \\
$\mathrm{Ti}(1)$ & 2.02 & 1.84 & 1.85 \\
$\mathrm{Ti}(2)$ & 2.02 & 1.52 & 1.54 \\
$\mathrm{O}(1)$ & -1.30 & -1.30 & -1.22 \\
$\mathrm{O}(4)$ & -1.30 & -1.33 & -1.30 \\
$\mathrm{O}(8)$ & -1.31 & -0.85 & -0.83 \\
$\mathrm{O}(9)$ & -1.31 & -1.27 & -1.29 \\
$\mathrm{H}(1)$ & - & 0.55 & 0.47 \\
\hline
\end{tabular}

of the electron density from the ions to the chemical bonds, leading to a more covalent character of the chemical bonding in the vicinity of the $\mathrm{H}$ impurity. This effect is especially obvious in the tetragonal phase of the crystal (table 6). This also coincides very well with the increase in some interatomic bond lengths in the defective region, leading to the outward atomic movements discussed in the previous section.

An analysis of the spin density reveals that a charge transfer has occurred from the inserted $\mathrm{H}$ impurity to the $\mathrm{Ti}$ and $\mathrm{O}$ atoms nearest to the defect. It is observed that the unpaired electron is occupying $\mathrm{Ti} 3 \mathrm{~d}_{z^{2}}$ and $\mathrm{O} 2 \mathrm{p}_{y}$ orbitals in the cubic structure and $\mathrm{Ti} 3 \mathrm{~d}_{x z}$ and $\mathrm{O} 2 \mathrm{p}_{x}$ orbitals in the tetragonal lattice. Thus one can see the hybridization between the Ti $3 \mathrm{~d}$ and $\mathrm{O} 2 \mathrm{p}$ orbitals, producing a more covalent nature in the chemical bonding around the $\mathrm{H}$ impurity. It is important to note 
the importance of precisely performed lattice relaxation. From tables 5 and 6 , it can be seen that the effective charges on atoms are quite different for the final configuration compared with the configuration not considering the lattice relaxation.

\section{4. $H$ effect on ferroelectric polarization}

An important issue concerning impurities and defects in ferroelectric crystals is their effect on the ferroelectric polarization. The $\mathrm{BaTiO}_{3}$ crystal exhibits ferroelectricity in its tetragonal phase and that is why we investigated possible bulk ferroelectricity changes due to the $\mathrm{H}$ insertion. Our qualitative study shows that the absolute values of the effective charges are reduced while the $\mathrm{Ti}-\mathrm{O}$ bond lengths increase considerably in the defective region. The first effect tries to reduce the electric dipole momentum while the second effect increases it. A simple calculation shows that the second effect, that is the increase in the $\mathrm{Ti}-\mathrm{O}$ bond length $\mathrm{is} 1.27$ times stronger. This indicates that the direction of the new dipole is favourably aligned with the host polarization. Thus, as a result, one can see an increase in the ferroelectric polarization in the $\mathrm{BaTiO}_{3}$ crystal due to the $\mathrm{H}$ impurity. The wellknown loss of ferroelectricity by $\mathrm{H}$ contamination thus is not a bulk effect. The primary damage is localized at the electrode-ferroelectric interface.

\section{§4. Conclusions}

The present periodic quantum-chemical calculations evaluate the structural and electronic properties of the $\mathrm{BaTiO}_{3}$ crystal due to the $\mathrm{H}$ impurity. The equilibrium spatial configurations obtained indicate the $\mathrm{O}-\mathrm{H}$ formation in the crystal. The $\mathrm{O}-\mathrm{H}$ bond lengths are found to be equal to 0.89 and $0.91 \AA$ in the cubic and tetragonal phases, respectively. Host $\mathrm{Ti}-\mathrm{O}$ bonds are found to be significantly weakened around a $\mathrm{H}$ impurity. This may provide an explanation for $\mathrm{O}$ loss in ferroelectric films near the surface under thermal annealing in a $\mathrm{H}_{2}$ atmosphere (Ikarashi 1998). O loss is enhanced around defective regions and especially at an interface where the hydroxyl ion can react chemically with the electrode (Han and Ma 1997). Damage at the metal-ferroelectric interface can prevent polarization switching and lead to a reduction in the switching charge of the ferroelectric capacitor. As a result of our study we can conclude that the degradation is not a bulk effect since the $\mathrm{H}$ impurity increases the bulk ferroelectric polarization.

\section{REFERENCES}

Aggarwal, S., Perusse, S. R., Tipton, C. W., Ramesh, R., Drew, H. D., Venkatesan, T., Romero, D. B., Podobedov, V. B., and Weber, A., 1998, Appl. Phys. Lett., 73, 1973. Erazo, F., and Stashans, A., 2000, Phil. Mag. B, 80, 1499.

FeinberG, J., 1982, J. opt. Soc. Am., 72, 46.

Feinberg, J., Heiman, D., Tanguay, A. R., JR, and Hellwarth, R. W., 1980, J. appl. Phys., 51, 1297.

Han, J.-P., and MA, T. P., 1997, Appl. Phys. Lett., 71, 1267.

Huber, K. P., and Herzberg, G., 1979, Molecular Spectra and Molecular Structure. Constants of Diatomic Molecules (New York: Van Nostrand).

IKarashi, N., 1998, Appl. Phys. Lett., 73, 1955.

Jacobs, P. W. M., and Kotomin, E. A., 1992, Phys. Rev. Lett., 69, 1411.

Jacobs, P. W. M., Kotomin, E. A., Stashans, A., and Tale, I. A., 1993, Phil. Mag. B, 67, 557.

Kantorovich, L., Stashans, A., Kotomin, E., and Jacobs, P. W. M., 1994, Int. J. quant. Chem., 52, 1177. 
Kotomin, E. A., Stashans, A., Kantorovich, L. N., Lifshitz, A. I., Popov, A. I., Tale, I. A., and Calais, J.-L., 1995, Phys. Rev. B, 51, 8770.

Krätzig, E., Welz, F., Orlowski, R., Doormann, V., and Rosenkranz, M., 1980, Solid St. Commun., 34, 817.

Kushida-Abdelghafar, K., Hiratani, M., and Fujisaki, Y., 1999, J. appl. Phys., 85, 1069.

Lunell, S., Stashans, A., Ojamäe, L. Lindström, H., and Hagfeldt, A., 1997, J. Am. chem. Soc., 119, 7374.

Park, C. H., and Chadi, D. J., 2000, Phys. Rev. Lett., 84, 4717.

Patiño, E., Erazo, F., and Stashans, A., 2001, Mater. Lett., 50, 337.

Persson, P., Stashans, A., Bergström, R., and Lunell, S., 1998, Int. J. quant. Chem., 70, 1055.

Pinto, H., and Stashans, A., 2000, Comput. Mater. Sci., 17, 73.

Pinto, H., Stashans, A., and Sánchez, P., 2000, Defects and Surface-Induced Effects in Advanced Perovskites, NATO Science Series, High Technology, Vol. 77 (Dordrecht: Kluwer), p. 67.

Press, W. H., Flannery, B. P., Teukolsky, S. A., and Vetterling, T., 1986, Numerical Recipes: The Art of Scientific Computing (Cambridge University Press).

Rytz, D., Wechsler, B. A., Garrett, M. H., Nelson, C. C., and Schwartz, R. N., 1990, J. opt. Soc. Am. B, 7, 2245.

Sánchez, P., and Stashans, A., 2001, Phil. Mag. B, 81, 1963.

Shluger, A., 1985, Theor. chim. Acta, 66, 355.

Shluger, A., and Stefanovich, E., 1990, Phys. Rev. B, 42, 9669.

Stashans, A., 2001, Mater. Chem. Phys., 68, 124.

Stashans, A., Erazo, F., Ortiz, J., and Valverde, P., 2001, Phil. Mag. B, 81, 1977.

Stashans, A., and Kitamura, M., 1996, Solid St. Commun., 99, 583; 1997, J. Phys. Chem. Solids, 58, 777.

Stashans, A., Kotomin, E., and Calais, J.-L., 1994, Phys. Rev. B, 49, 14854.

Stashans, A., and Lunell, S., 1996, Int. J. quant. Chem., 63, 729.

Stashans, A., Lunell, S., Bergström, R., Hagfeldt, A., and Lindquist, S.-E., 1996a, Phys. Rev. B, 53, 159.

Stashans, A., Lunell, S., and Grimes, R. W., 1996b, J. Phys. Chem. Solids, 57, 1293.

Stashans, A., and Pinto, H., 2000, Int. J. quant. Chem., 79, 358.

Stefanovich, E. V., Shidlovskaya, E. K., Shluger, A. L., and Zakharov, M. A., 1990, Phys. Stat. sol. (b), 160, 529.

Zafar, S., Kaushik, V., Laberge, P., Chu, P., Jones, R. E., Hance, R. L., Zurcher, P., White, B. E., Taylor D., Melnick, B., and Gilespie, S., 1997, J. appl. Phys., 82, 4469.

Zhukovskit, Yu. F., Kotomin, E. A., Nieminen, R. M., and Stashans, A., 1997, Comput. Mater. Sci., 7, 285. 